Research

Elsevier Editorial System(tm) for Fisheries Manuscript Draft

Manuscript Number: FISH8212R1

Title: Could green artificial light reduce bycatch during Barents sea Deep-water shrimp trawling?

Article Type: Research Paper

Keywords: Bottom trawl; Bycatch; LEDs; Nordmøre grid; Pandalus borealis; Size selectivity

Corresponding Author: Mr. Roger B. Larsen, MSc fisheries science

Corresponding Author's Institution: University of Tromsö

First Author: Roger B. Larsen, MSc fisheries science

Order of Authors: Roger B. Larsen, MSc fisheries science; Bent Herrmann; Manu Sistiaga; Jure Brcic; Jesse Brinkhof; Ivan Tatone

Manuscript Region of Origin: NORWAY 


\section{Could green artificial light reduce bycatch during Barents Sea}

\section{Deep-water shrimp trawling?}

3 Roger B. Larsen ${ }^{1 a^{*}}$, Bent Herrmann ${ }^{1,2^{*}}$, Manu Sistiaga ${ }^{2 *}$, Jure Brčić ${ }^{3 *}$, Jesse Brinkhof ${ }^{1,2}$, Ivan 4 Tatone $^{1}$.

$5{ }^{1}$ The Arctic University of Norway, UiT, Breivika, N-9037 Troms $\varnothing$, Norway

$6 \quad{ }^{2}$ SINTEF Fisheries and Aquaculture, Brattørkaia 17C, N-7010 Trondheim, Norway

$7 \quad{ }^{3}$ University of Split, Department of Marine Studies, 21000 Split, Croatia

$8 \quad{ }^{\mathrm{a}}$ Corresponding author. Tf: +4777644536

$9 \quad$ *Equal authorship.

E-mail address: roger.larsen@uit.no

\section{Abstract}

The Nordmøre grid is widely used in shrimp trawls to reduce the bycatch of fish species.

However, small-sized fish species and juveniles still pass through the grid and enter the codend, along with the targeted shrimp. This bycatch of small fish has a negative impact on the ecosystem due to increased fish mortality, and leads to additional sorting work onboard. Some small-sized fish that enter the trawl avoid entering the codend by escaping through the outlet above the grid, without making contact with the grid itself. Design changes that promote this behavior could potentially reduce bycatch in shrimp trawl fisheries. Lightemitting diodes (LEDs) mounted around the escape outlet have previously been found to have either a negative effect, or no effect at all, on fish bycatch species. This study investigates the effect of mounting green LEDs on the lower part of a Nordmøre grid, to determine if their presence would encourage bycatch fish to rise towards the escape outlet prior to contacting the grid. Experimental fishing trials were conducted to assess the size selective properties of a $19 \mathrm{~mm}$ bar spaced Nordmøre grid with and without LEDs, mounted on a bottom trawl targeting Deep-water shrimp (Pandalus borealis). For the four bycatch species investigated, $51-100 \%$ of small fish passed through the Nordmøre grid. The addition of green LEDs to the Nordmøre grid did not significantly affect the escape probability or the size selectivity of any 
of the investigated species. Very few Deep-water shrimp were found to escape through the escape outlet independent of the presence of the LEDs mounted on the grid.

Keywords: Bottom trawl; Bycatch; LEDs; Nordmøre grid; Pandalus borealis; Size selectivity

\section{Introduction}

The Nordmöre grid is widely used in shrimp trawls to reduce fish bycatch (Broadhurst, 2000; He and Balzano, 2011). However, substantial quantities of small fish species and juveniles can pass through the grid and enter the small-meshed codend along with the targeted shrimp (He and Balzano, 2007). This is a problem also in the Norwegian trawl fishery targeting Deep-water shrimp (Pandalus borealis) in the Barents Sea (Larsen et al., 2017). The Deepwater shrimp is a commercially important species, and has been fished since the beginning of the $20^{\text {th }}$ century in all Nordic countries. The international trawl fishery in the Barents Sea is often associated with a juvenile fish bycatch problem (Gullestad et al., 2015), mainly due to the small codend mesh size used in the fishery (minimum $35 \mathrm{~mm}$ ). Bycatches of juvenile and undersized fish from various species of commercial interest can be significant during periods of the year in the Norwegian Deep-water shrimp fishery. These catches can have a negative effect on the ecosystem and represent an unintended ecosystem impact of the fishery (Gullestad et al., 2017). The Nordmøre grid was initially developed to exclude jellyfish from catches, but is also efficient in excluding bycatch fish species during shrimp trawling (Isaksen et al., 1992). Legislation introduced in Norway in 1991, and internationally in 1993, requiring the use of the Nordmøre grid eliminated the issue of larger sized fish in bycatch. However, smaller fish, often juveniles, are still able to pass through the $19 \mathrm{~mm}$ bar spaced grid into the codend, together with the targeted shrimp. The Nordmøre grid system as used in Norway consists of a section with guiding panel, a sorting grid and a fish escape opening in front of the grid (Norwegian Directorate of Fisheries, 2017). 
The current regulations in the Northeast Atlantic shrimp fishery allow the retention of low numbers of juveniles of commercially important species. A fishing area is closed if the authorities register that a fishing vessel is catching more than eight individuals of cod (Gadus morhua), 20 haddock (Melanogrammus aeglefinus), three redfish (Sebastes spp.), or three Greenland halibut (Reinhardtius hippoglossoides) per $10 \mathrm{~kg}$ of shrimp (Norwegian Directorate of Fisheries, 2011). These strict bycatch rules have led to frequent closures of large shrimp fishing grounds in the Northeast Atlantic in recent years. Closures can last for weeks or months, often resulting in huge operational problems and increased costs for the fishing fleet, i.e. longer distances between potential fishing grounds due to area closures. The bycatch of juvenile fish also causes practical problems, such as increased catch sorting time onboard fishing vessels.

Underwater observations have shown that some small fish avoid entering the codend by seeking the escape outlet in the upper panel in front of the Nordmøre grid without making contact with the grid (Larsen, pers. comm.). Therefore, apart from the obvious effect of changing the grid bar spacing (Grimaldo and Larsen, 2005), other changes in the grid section design that affects the ratio of juvenile fish seeking the outlet without contacting the grid could reduce the bycatch of small-sized fish.

The use of light-emitting diodes (LEDs) can have an effect on fish behavior (Hannah et al., 2015). In a recent study using various colors of Lindgren-Pitman Electralume ${ }^{\circledR}$ LEDs, Nguyen et al. (2017) found that lights in the lower luminescence spectra, at peak wavelengths 464 and $519 \mathrm{~nm}$ (blue and green, respectively), and white LEDs, significantly increased the catch of Snow crab (Chionoecetes opilio) during field experiments. During trials on cod pots in the Baltic Sea, Bryhn et al. (2014) found that green light resulted in significant increases in both the number and size of fish caught. A number of studies have demonstrated the potential for this type of stimulation to influence the selective properties of trawl gear. For example, 
Rose and Hammond (2014) found that attaching green Lindgren-Pitman Electralume LEDs to the footrope of a survey trawl resulted in an increased escape rate for Southern Rock sole (Lepidopsetta bilinetata). Hannah et al. (2015) reported that attaching LEDs to shrimp trawl footgear and illuminating the escape path under the net resulted in a bycatch reduction of 50 $90 \%$ depending on the fish species. The authors also attached similar LEDs close to the Nordmøre grid, resulting in a significant increase in the bycatch of eulachon (Thaleichthys pacificus). Despite this negative effect, the authors discuss the possibility that illumination of the grid face by artificial light may help other small fish to escape (Hannah et al., 2015).

LEDs mounted around the Nordmøre grid escape outlet have been tested to determine if they could promote bycatch escape through the outlet, avoiding grid contact, in Northeast Atlantic shrimp fishery (Larsen et al., 2017). A significant reduction in the probability of seeking the escape outlet was reported for haddock, but not for other species. However, the study had a small sample size, leading to wide confidence intervals in the results for the species investigated. Based on the results obtained by Larsen et al. (2017), it can be speculated that fish are scared by the LEDs in the upper part of the grid section and therefore discouraged from escaping through the outlet. Following on from this, the current study investigated the effect of mounting green LEDs on the lower part of the Nordmøre grid to examine if this would encourage bycatch species to rise towards the outlet and escape without contacting the grid.

\section{Materials and Methods}

\subsection{Experimental design}

Fishing trials were performed on board the research trawler (R/V) "Helmer Hanssen" (63.8 m overall length and $4080 \mathrm{HP}$ ) during $19^{\text {th }}-22^{\text {nd }}$ of November 2016. The study area was located in the Northeast of the Barents Sea and the experiments were made within an area of $17 \times 5$ 
nautical miles $\left(\mathrm{N}_{75^{\circ}} 30^{\prime}-\mathrm{E} 30^{\circ} 10^{\prime}\right.$ to $\left.\mathrm{N} 75^{\circ} 13^{\prime}-\mathrm{E} 29^{\circ} 50^{\prime}\right)$. The location for the trials is with sun below horizon in the period $29^{\text {th }}$ October to $7^{\text {th }}$ February and with a depth of $363-381 \mathrm{~m}$ we therefore assumed darkness at the fishing depth any time of the day. The fishing trials were carried out using an Egersund Polar 2800\# trawl and a pair of Injector Scorpion doors (8 $\mathrm{m}^{2}$, $3100 \mathrm{~kg}$ ). The trawl and doors were linked by $40 \mathrm{~m}$ long double sweeps. The ground-gear attached to the fishing line was a $19.2 \mathrm{~m}$ long rockhopper constructed of three sections with $\emptyset 53 \mathrm{~cm}$ rubber discs. In Table 1 it is explained how we executed the hauls with and without artificial lights.

The trawl was equipped with a four-panel Nordmøre grid section, equivalent in dimensions and construction to the two-panel standard Nordmøre grid section (Norwegian Directorate of Fisheries, 2017), which is used by the Norwegian coastal fleet targeting shrimp. The grid was made of stainless steel ( $1.50 \mathrm{~m}$ high and $0.75 \mathrm{~m}$ wide $)$ and was mounted to maintain an angle of $45^{\circ} \pm 2.5^{\circ}$ while fishing. The bar spacing in the Nordmøre grid was measured using a caliper following the guidelines in Wileman et al. (1996), and recorded as $18.73 \pm 0.14 \mathrm{~mm}$ (mean \pm standard deviation). A triangular escape outlet was cut out of the top panel of the grid section. It measured 35 meshes long (by $52 \mathrm{~mm}$ mesh length) and 70 meshes wide equaling a triangle ca. $1.6 \mathrm{~m}$ long and $0.75 \mathrm{~m}$ wide, reinforced with a $\emptyset 10 \mathrm{~mm}$ PE rope (Fig. 1A). To collect fish and shrimp escaping through the escape outlet before reaching the grid, a small meshed cover (mesh size $18.9 \pm 1.2 \mathrm{~mm}$ ) was mounted over the escape outlet (Fig. 1B), following the guidelines in Wileman et al. (1996). Fish and shrimp that passed through the grid were collected in the codend, which contained a small mesh inner net (mesh size $18.5 \pm$ $0.9 \mathrm{~mm}$ ) installed with a low hanging ratio to prevent fish and shrimp from escaping. To prevent blocking the grid outlet with the cover, the latter was supported with five $\varnothing 200 \mathrm{~mm}$ plastic floats (each of $2.7 \mathrm{~kg}$ lifting capacity).

\section{FIG 1}




$$
p\left(l, C_{\text {grid }}, L 50_{\text {grid }}, S R_{\text {grid }}\right)=\frac{C_{\text {grid }}}{1.0+\exp \left(\frac{\ln (9)}{S R_{\text {grid }}} \times\left(l-L 50_{\text {grid }}\right)\right)}
$$
measured to the nearest $\mathrm{mm}$ using callipers.

Two different trawl configurations were tested during experimental fishing (Fig. 2):

- Standard configuration without LEDs. downwards (at a $45^{\circ}$ angle).

FIG. 2

\subsection{Model for size selection} shrimp or fish passing through the Nordmøre grid and entering the codend $(p(l))$ :

The catch from the cover over the grid outlet and the codend was each separately sorted by species, and all by-catch fish species were measured to the nearest $\mathrm{cm}$. No subsampling was carried out for any of the fish species. The shrimp catch was subsampled, as it was not possible to measure all shrimp caught. A random portion of approximately $1 \mathrm{~kg}$ of the shrimp catch in each compartment was taken as a subsample. The carapace length of the shrimp was

- Standard configuration with four green Lindgren-Pitman Electralume® LEDs attached to the lower part of the Nordmøre grid with LEDs pointing in towing direction and

Larsen et al. (2017) used the following model to determine the size dependent probability of a

As the experimental design in the current study is similar to that used by Larsen et al. (2017), the same model is used to describe the size dependent probability of bycatch fish species and shrimp passing through the Nordmøre grid. In model (1) $l$ represents fish length or shrimp carapace length. The probability of making contact with the grid is modeled by the length independent parameter $C_{\text {grid }}$ which can have a value ranging from of 0.0 to 1.0. An estimated $C_{\text {grid }}$ value of 1.0 for a species means that every individual of that species contacts the grid in a way that gives them a length-dependent chance of passing through the grid. For fish or 
shrimp making contact with the grid, $L 50_{\text {grid }}$ denotes the length at which there is a $50 \%$ probability of being prevented from passing through, and $S R_{\text {grid }}$ describes the difference in length between individuals with respectively $75 \%$ and $25 \%$ probability of being prevented from passing through the grid. Further details on model (1) can be found in Larsen et al. (2017).

To examine how both of the Nordmøre grid configurations performed on average, analysis was carried out on data summed over all hauls. The analysis was conducted separately for each Nordmøre grid configuration based on the data from the hauls with the specific configuration and separately for each species. Thus, expression (2) was minimized, which is equivalent to maximizing the likelihood for the observed data in the form of the lengthdependent number of individuals measured as retained in the codend $\left(n C_{l}\right)$, versus the number collected in the Nordmøre grid cover $\left(n G_{l}\right)$.

$-\sum_{j=1}^{m} \sum_{l}\left\{\frac{n C_{j l}}{q C_{j}} \times \ln \left(p\left(l, C_{\text {grid }}, L 50_{\text {grid }}, S R_{\text {grid }}\right)\right)+\frac{n G_{j l}}{q G_{j}} \times\right.$

$\left.\ln \left(1.0-p\left(l, C_{\text {grid }}, L 50_{\text {grid }}, S R_{\text {grid }}\right)\right)\right\}$

In (2), $q C_{j}$ and $q G_{j}$ represent the sampling factors for the fraction of individuals that were length measured in the blinded codend and grid cover for each haul $j$. The sampling factors can range in value from 0.0 to 1.0 (1.0 if all individuals are length measured). The outer summation in (2) is over the hauls conducted with the specific Nordmøre grid configuration and the inner summation is over length classes in the data (Larsen et al., 2017).

The ability of the model (1) to describe the data was based on calculating the corresponding p-value. A p-value greater than 0.05 implies that the model fits the data sufficiently well. In case of poor fit statistics ( $\mathrm{p}$-value $<0.05$ ), the deviance versus the degrees of freedom and the residuals were inspected to determine whether the poor result was due to structural problems when modelling the experimental data, or over-dispersion in the data (Wileman et al., 1996). 
173 Efron $95 \%$ percentile confidence bands (Efron, 1982) for the grid passage probability curve 174 (model (1)), and the parameters in it $\left(C_{\text {grid }}, L 50_{\text {grid }}, S R_{\text {grid }}\right)$, were obtained using a double 175 bootstrap method implemented using the software tool SELNET (Herrmann et al., 2012). For each species and grid configuration analyzed, 1000 bootstrap repetitions were conducted to estimate the $95 \%$ confidence limits (Efron percentile) (see Larsen et al., 2017 for further details).

To infer the effect of mounting the LEDs to the Nordmøre grid, the difference in the lengthdependent grid passage probability $\Delta p(l)$ was estimated:

$\Delta p(l)=p_{L E D}(l)-p_{\text {Base }}(l)$

where $p_{\text {Base }}(l)$ is the grid passage probability obtained for the configuration without LEDs mounted and $p_{L E D}(l)$ is the grid passage probability obtained for the configuration with mounted LEDs. The $95 \%$ confidence intervals for $\Delta p(l)$ were obtained based on the two bootstrap population results (1000 bootstrap repetitions in each) for $p_{B a s e}(l)$ and $p_{L E D}(l)$, respectively. As they are obtained independently from each other, a new bootstrap population of results for $\Delta p(l)$ was created using:

$\Delta p(l)_{i}=p_{L E D}(l)_{i}-p_{\text {Base }}(l)_{i} i \in[1 \ldots 1000]$

where $i$ denotes the bootstrap repetition index. As resampling was random and independent for both groups of results, it is valid to generate the bootstrap population of results for the difference based on (4) using two independently generated bootstrap files (Moore et al., 2003). Based on the bootstrap population, Efron $95 \%$ percentile confidence limits were obtained for $\Delta p(l)$ as described above. In general, the confidence limits for $\Delta p(l)$ cannot exceed what is spanned by $p_{B a s e}(l)$ and $p_{L E D}(l)$ together and will often be smaller (Moore et al., 2003). Therefore, using this approach will increase the power of inference of the effect of mounting LEDs to the Nordmøre grid compared to the simple strategy based on the search for 
non-overlapping confidence limits between the two curves for the grid passage probability. All analyses described above were conducted using the analysis tool SELNET (Herrmann et al., 2012).

\section{Results}

\subsection{Collected data}

During the trials, a total of 16 hauls were carried out, eight with the standard configuration and eight with the LED configuration (Table 1). Trawling time was kept as constant as possible, and was approximately 2 hours for all 16 hauls. Four important bycatch fish species were caught in sufficient numbers during the trials to be included in the investigation and the length of each individual was measured. A total of 4908 redfish, 3834 American plaice (Hippoglossoides platessoides), 1655 cod and 674 haddock were measured (Table 1). The Deep-water shrimp had to be subsampled (subsampling ratios varied from $2.32 \%$ to 100.00 $\%)$ and a total of 4613 individuals were measured.

\section{TABLE 1}

Overall, the results for the four bycatch species showed that $51-100 \%$ of small fish passed through the Nordmøre grid. See $C_{\text {grid }}$ values in Table 2 and sections 3.2.-3.6 for further details.

\section{TABLE 2}

FIG. 3

\subsection{Size selectivity and grid passage probability for American plaice}

For American plaice, the fit statistics showed that model (1) described the experimental data well, as p-values were over 0.05 (Table 2), and the fitted curves followed the trends in the experimental data well for both configurations tested (Fig. 3). The values for $C_{\text {grid }}$ were very 
high at 99-100\%, meaning that only 0-1\% of the American plaice that entered the gear would escape through the outlet without first contacting the grid. $C_{\text {grid }}$ did not differ significantly between the two configurations tested (Table 2), as the confidence intervals completely overlapped. Almost all of the American plaice in the size range 4-32 cm passed through the Nordmøre grid with a continuously decreasing passage probability reaching zero at around $32 \mathrm{~cm}$ (Fig. 3). Therefore, American plaice up to $32 \mathrm{~cm}$ in length have a high risk of being caught in a trawl using a Nordmøre grid with $19 \mathrm{~mm}$ bar spacing. The estimated $L 50_{\text {grid }}$ values combined with the estimated $C_{\text {grid }}$ values imply that approximately $50 \%$ of the American plaice that enter the trawl pass through the Nordmøre grid into the codend. The estimated $S R_{\text {grid }}$ values were relatively large, around $40-45 \%$ of the $L 50_{\text {grid }}$ value (Table 2). This is likely due to the variety of different ways in which flatfish contact the grid and could explain the low slope of the grid passage curve (Fig. 3). This type of process has previously been successfully applied to explain size selection of Greenland halibut in fish sorting grids (Herrmann et al., 2013), and similar process can be expected for American Plaice. The difference in retention probability between the two designs (Delta plot, Fig. 3) exhibit almost identical curves, demonstrating that the addition of LEDs to the grid did not affect the grid passage probability for American plaice.

\subsection{Size selectivity and grid passage probability for cod}

The fit statistics showed that for cod, model (1) described the experimental data well for the standard and LED configurations, with p-values greater than 0.05 (Table 2). $C_{\text {grid }}$ values were high, at over $70 \%$, with no significant difference between designs, resulting in the majority of the smallest sizes of cod $(<15 \mathrm{~cm})$ passing through the Nordmøre grid and into the codend. For cod between 15 and $25 \mathrm{~cm}$, the grid passage probability decreased gradually with increasing size (Fig. 3), and no cod above $25 \mathrm{~cm}$ entered the codend. The two grid passage probability curves are nearly identical (Delta plot, Fig. 3) and not significantly different from 
0.0 for any sizes of cod. This implies that adding LEDs to the Nordmøre grid does not significantly affect the grid passage probability for this species.

\subsection{Size selectivity and grid passage probability for haddock}

For haddock, the power in the experimental data was weaker compared to the other species investigated, as fewer individuals were caught (Table 1). This resulted in wider confidence bands, which prevented inferences on haddock. Since confidence intervals for the curve in the delta plot contained 0.0 (Fig. 3), no effect was detected for haddock by mounting LEDs on the Nordmøre grid. At least $40 \%$ of haddock up to approximately $15 \mathrm{~cm}$ pass through the grid into the codend when fishing with the standard configuration. For haddock over $15 \mathrm{~cm}$, this risk gradually decreases with length, reaching zero for haddock over $18 \mathrm{~cm}$. The fit statistics showed that model (1) was capable of describing the experimental data well for both configurations as the p-values were above 0.05 in each case (Table 2).

\subsection{Size selectivity and grid passage probability for redfish}

In the case of redfish, the fit statistics showed that model (1) described the experimental data collected with both configurations well (Table 2$)$. The grid contact values $\left(C_{\text {grid }}\right)$ were high, at over $70 \%$, with no significant difference between designs, resulting in the majority of the small redfish $(<12 \mathrm{~cm})$ passing through the Nordmøre grid into the codend. For redfish between 12 and $20 \mathrm{~cm}$, grid passage probability decreases gradually with increasing fish size (Fig. 3), and no redfish over $20 \mathrm{~cm}$ entered the codend. The grid passage probability curves for the two configurations were not significantly different, as the $95 \%$ confidence intervals of the curves for their delta contained 0.0 for all sizes of redfish. The results imply that mounted LEDs did not significantly affect size selection for this species.

\subsection{Size selectivity and grid passage probability for Deep-water shrimp}


The fit statistics showed that model (1) described the experimental data well for Deep-water shrimp for the standard configuration, as the p-value was estimated to be $>0.05$ (Table 2). For the LED configuration, the p-value was low. However, since there was no clear pattern in the deviations between the data points and the fitted grid passage probability curve, this result was attributed to over-dispersion in the data. This over-dispersion was probably due to the amount of subsampling required during the shrimp data collection process (Table 1). Therefore, the model (1) can also be used to describe the length-dependent grid passage probability for this species (Fig. 3). The Nordmøre grid passage probability was very high for both configurations tested (Fig. 3). This is also illustrated by the high $C_{\text {grid }}$ values, which were estimated to be $100 \%$ in both cases, with relatively high values for the lower confidence limits (Table 2). This was also reflected in the confidence limits for the grid passage probability curves, which were very similar and contained 0.0 for all sizes of Deep-water shrimp in the Delta plot (Fig. 3). The results show that LEDs have no effect on the grid passage probability of Deep-water shrimp. While the grid passage probabilities are high, both curves show a slight decrease with the size of the shrimp.

\section{Discussion}

Using the Barents Sea Deep-water shrimp fishery as a case study, it was investigated if it was possible to change fish behavior in front of the Nordmøre grid, by triggering fish to utilize the escape outlet above the grid, completely avoiding contact with the grid. Recent studies have reported that fish display an avoidance response to certain colors of LEDs (Rose and Hammond, 2014; Hannah et al., 2015). However, it was not known how effective LEDs mounted on the Nordmøre grid would be in triggering the desired fish behavior in this fishery. This study aimed to quantify the Nordmøre grid passage probability for different bycatch species of different sizes, and to determine if mounting LEDs in the lower part of the grid could reduce the amount of fish bycatch in the fishery. 
The results of this study determined that there is a high grid passage probability for small individuals of American plaice, cod, haddock and redfish, meaning that high numbers of juveniles are likely to be retained by the codend. Adding green LEDs to the Nordmøre grid did not reduce the risk for any of the species investigated passing through the Nordmøre grid. In fact, adding LEDs to the grid did not significantly affect the size selectivity for any of the bycatch species. While it was possible to answer the formulated research questions in this study, the results do not suggest a technical measure for bycatch reduction in shrimp trawl fisheries based on utilizing LEDs mounted on the base of the Nordmøre grid. The green LEDs used in these trials did not result in a reduction of bycatch, thus confirming previous results from the northeast Atlantic (Larsen et al., 2017). Hannah et al. (2015) reported that the addition of green LED lamps around the grid increased the bycatch of eulachon by $104 \%$ and slender sole (Lyopsetta exilis) by $77 \%$, but the artificial light had no effect on ocean shrimp (Pandalus jordani) and other fishes. Despite our results to some extent are in line with Hannah et al. 2015, we did not find significant increase in bycatch for any of the species examined. The possibility that the green LEDs affected the behavior of juvenile fish species recorded in this study cannot be discounted.

In the standard Nordmøre grid setup the distance between the guiding panel and the grid is 0.5 m (Fig. 3), and the water flow (i.e. relative velocity) through it is more than $80 \%$ of the towing speed (Grimaldo and Larsen, 2005), i.e. more than 2.5 knots in our experiments. As small fish have a limited swimming capacity in the aft part of a bottom trawl (Winger et al., 2010), it is assumed that most of the small fish (ca. 10-20 cm) are unable to maneuver away from the water flow through the lower part of the grid. This effect is supported by the high $C_{\text {grid }}$ values (Table 2). It is therefore concluded that other technical measures for reducing the risk of bycatch in this fishery need to be found. He and Balzano (2013) state that exclusion of fish bycatch by the Nordmøre grid can be attributed more to size and morphology than 
behaviour of the animal and that small fish species in size are more difficult to exclude from the trawl once they enter. Their rope grid design which is based on utilizing water flow and swimming ability of fish reduced the catches of both small shrimps and finfish, especially finfish larger than $16 \mathrm{~cm}$ (He and Balzano, 2013).

Norwegian-Russian legislation for northern fisheries requires improved selectivity in any type of bottom trawls (Hønneland, 2014). Fishing fleets, supported by fisheries management, are therefore constantly seeking solutions to improve the bycatch mitigation, i.e. the species selectivity of the gear. In the case of the Deep-water shrimp fishery, increased selectivity would benefit the industry, as it would result in less mechanical sorting on board, and a reduction in area closures when bycatch levels exceeds given criteria. For the management of the northeast Atlantic fisheries and as part of the priority list on fishery-related issues regarding selectivity and discards, there is an ongoing revision of criteria for the intermixture of juveniles and testing of new concepts to reduce such by-catches in the shrimp fisheries north of $62^{\circ} \mathrm{N}$ (Gullestad et al., 2017).

Although the results of this study found that the addition of LEDs had no significant effect on the amount of bycatch in the codend; as a result, the present findings are to all effects negative. However, reporting this type of results does have a value both from the scientific and the fishing industry viewpoint, because they enhance our understanding of fishing gear selectivity besides reducing the risk of testing the same non-functioning concepts several times. In addition, publishing negative as well as favorable results prevents forming a biased picture (Csada et al., 1996). Therefore, even though the proposed solution did not deliver the intended gain in bycatch reduction, we feel it still provides a useful contribution to the literature.

The results for the standard configuration are important, as they quantify the risk of various sizes of bycatch species being caught along with shrimp if they are abundant on the fishing 
grounds. The results for this configuration are in line with those reported by Larsen et al. (2017) who also tested this configuration as baseline to investigate the effect of other design changes. The high $C_{\text {grid }}$ values for bycatch species in the standard configuration both in the this study and in Larsen et al. (2017) illustrate the challenge to avoid the small sized fish in this shrimp fishery if they are abundant on the fishing grounds. Especially for the only flatfish species in our study, American plaice, the values for $C_{\text {grid }}$ were very high at $99-100 \%$, meaning that only $0-1 \%$ of the American plaice that entered the gear would escape through the outlet without first contacting the grid. This is in keeping with the expectation that flatfish show a preference for staying low in the gear, and therefore their length-dependent grid passage probability does not exhibit the characteristic plateau (constant value for individuals up to a certain size) seen for other species. The results for the standard configuration is important for fisheries managers, who have two mitigation options: 1) closing fishing grounds for a certain period, or 2) enforcing the use of codends that enable the release of fish with the highest risk of passing through the grid. The first mitigation option has significant consequences on the operational possibilities of the fleet, but is simpler to apply. The latter mitigation strategy needs to be carefully considered, taking into account codend size selection of the targeted shrimp.

\section{Acknowledgements}

We thank the crew of RV "Helmer Hanssen" and Richard Buvang, Frode Gerhardsen, Helene Gjesteland, Tom Andreassen, Hanna Danielsen and Kristoffer Andreassen for valuable assistance on board. We are also grateful to the Arctic University of Norway (UiT) in Troms $\varnothing$, the Norwegian Directorate of Fisheries and the Norwegian Seafood Research Fund (project no. 901303) for funding the experiments carried out in this study. The anonymous reviewers who made helpful comments and corrections in improving this manuscript are greatly appreciated. 


\section{References}

369 Broadhurst, M. K., 2000. Modifications to reduce bycatch in prawn trawls: A review and framework for development. Rev. Fish Biol. Fish. 10, 27-60.

371

Bryhn, A. C., Königson, S., Lunneryd, S.G., Bergenius, M., 2014. Green lamps as visual stimuli affect the catch efficiency of floating cod (Gadus morhua) pots in the Baltic Sea. Fish. Res. 157, 187-192.

Csada, R.D., James, P.C., Richard, H.M.E., 1996. The "File Drawer Problem" of NonSignificant Results: Does It Apply to Biological Research? Oikos 76, 591-593.

Efron, B., 1982. The jackknife, the bootstrap and other resampling plans. SIAM Monograph No. 38. CBSM-NSF, Regional Conference Series in Applied Mathematics, Philadelphia.

Grimaldo, E., Larsen, R.B., 2005. The cosmos grid: A new design for reducing by-catch in the Nordic shrimp fishery. Fish. Res. 76, 187-197.

Gullestad, P., Blom, G., Bakke, G., Bogstad, B., 2015. The "Discard Ban Package”:

Experiences in efforts to improve the exploitation patterns in Norwegian fisheries. Mar. Pol. $54,1-9$

Gullestad, P., Abotnes, A.M., Bakke, G., Skern-Mauritzen, M., Nedreaas, K., Søvik, G., 2017. Towards ecosystem-based fisheries management in Norway - Practical tools for keeping track of relevant issues and prioritising management efforts. Mar. Pol. 77, 104-110.

Hannah, R.W., Lomeli, M.J.M., Jones S.A., 2015. Tests of artificial light for bycatch reduction in an ocean shrimp (Pandalus jordani) trawl: Strong but opposite effects at the footrope and near the bycatch reduction device. Fish. Res., 170, 60-67.

He, P., Balzano, V., 2007. Reducing the catch of small shrimp in the Gulf of Maine pink shrimp fishery with a size-sorting grid device. ICES J. Mar. Sci. 64, 1551-1557. 
He, P., Balzano, V., 2011. Rope Grid: A new grid design to further reduce finfish bycatch in the Gulf of Maine pink shrimp fishery. Fish. Res. 111, 100-107.

He, P., Balzano, V., 2013. A new shrimp trawl combination grid system that reduces small shrimp and finfish bycatch. Fish. Res. 140, 20-27.

Herrmann, B., Sistiaga, M.B., Nielsen, K.N., Larsen, R.B., 2012. Understanding the size selectivity of redfish (Sebastes spp.) in North Atlantic trawl codends. J. Northw. Atl. Fish. Sci. 44, 1-13.

Herrmann, B., Sistiaga, M., Larsen, R.B., Nielsen, K.N., Grimaldo, E., 2013. Understanding sorting grid and codend size selectivity of Greenland halibut (Reinhardtius hippoglossoides). Fish. Res. 146, 59-73.

Hønneland, G., 2014. Norway and Russia: Bargaining Precautionary Fisheries Management in the Barents Sea. Arctic Rev. 5, 75-99.

Isaksen, B., Valdemarsen, J.W., Larsen, R.B., Karlsen, L., 1992. Reduction of fish by-catch in shrimp trawl using a rigid separator grid in the aft belly. Fish. Res. 13, 335-352.

Larsen, R.B., Herrmann, B., Sistiaga, M., Brinkhof, J. Tatone, I., Langård, L., 2017.

Performance of the Nordmøre grid in shrimp trawling and potential effects of guiding funnel length and light stimulation. Mar. Coast. Fish, dx.doi.org/10.1080/19425120.2017.1360421.

Larsen, personal communication. Roger B. Larsen, The Arctic University of Norway, UiT, Breivika, N-9037 Troms $\varnothing$, Norway.

Moore, D.S, McCabe, G.P., Duckworth, W.M., Sclove, S.L, 2003. Practice of Business

Statistics using data for decisions. Published by W. H. Freeman. ISBN 10: 0716757230 / ISBN 13: 9780716757238. 
413 Nguyen, K.Q., Winger, P.D., Morris, C., Grant, S.M., 2017. Artificial lights improve the 414 catchability of snow crab (Chionoecetes opilio) traps. Aqua. Fish. 2, 124-133.

415 Norwegian Directorate of Fisheries, 2011. J-209-2011: Forskrift om maskevidde, bifangst og 416 minstemål m.m. ved fiske i fiskevernsonen ved Svalbard (In Norwegian).

417 Norwegian Directorate of Fisheries, 2017. J-182-2017: Forskrift om utforming og 418 innmontering av sorteringsrist i reketrål (In Norwegian ).

419 Rose, C. and Hammond, C.F., 2014. Addition of light to an experimental footrope caused 420 increased escapement of one flatfish species. In: ICES. 2014. First Interim Report of the 421 ICES-FAO Working Group on Fishing Technology and Fish Behavior (WGFTFB), 5-9 May 422 2014, New Bedford, USA. ICES CM 2014/SSGESST:08. 140 pp.

423 Wileman, D. A., Ferro, R. S. T., Fonteyne, R., and Millar, R. B. (Eds.), 1996. Manual of 424 methods of measuring the selectivity of towed fishing gears. ICES Coop. Res. Rep. No. 215.

425 Winger, P.D. Eayrs, S. and Glass C.W., 2010. Fish behavior near bottom trawls. In: He, P., 426 2010. Behavior of marine fishes: capture processes and conservation challenges, pp. 65-103. 427 Wiley-Blackwell. ISBN: 978-0-813-81536-7. 


\section{Table legends}

Table 1: Overview of the 16 hauls with dates (day and month), hour and minute for the start of the hauls, towing time by minutes and number of length measurements obtained for fish and shrimp. The values in brackets represent the sampling factors (\% in weight measured). Length measurements were taken for all fish caught. * indicates that data were not collected due to damage, making length measurement impossible. $n C$ is the number of individuals in the codend and $n G$ is the number of individuals in the grid cover. Hauls 5 to 12 were made with LED lamps.

\begin{tabular}{|c|c|c|c|c|c|c|c|c|c|c|c|c|c|}
\hline \multirow[t]{2}{*}{$\begin{array}{l}\text { Haul } \\
\text { ID }\end{array}$} & \multirow[t]{2}{*}{ Date } & \multirow[t]{2}{*}{$\begin{array}{l}\text { Start } \\
\text { haul }\end{array}$} & \multirow[t]{2}{*}{$\begin{array}{l}\text { Towing } \\
\text { time }\end{array}$} & \multicolumn{2}{|c|}{ Redfish } & \multicolumn{2}{|c|}{$\begin{array}{c}\text { American } \\
\text { Plaice }\end{array}$} & \multicolumn{2}{|c|}{ Cod } & \multicolumn{2}{|c|}{ Haddock } & \multicolumn{2}{|c|}{ Deep-water Shrimp } \\
\hline & & & & $n C$ & $n G$ & $n C$ & $n G$ & $n C$ & $n G$ & $n C$ & $n G$ & $\begin{array}{c}n C(\% \\
\text { measurd) }\end{array}$ & $\begin{array}{c}n G(\% \\
\text { measured) }\end{array}$ \\
\hline 1 & 19.11. & 05:31 & 70 & 15 & 77 & 55 & 74 & 29 & 45 & 14 & 11 & $210(8.18)$ & $264(54.50)$ \\
\hline 2 & 19.11. & 07:44 & 120 & 328 & 627 & 58 & 97 & 149 & 72 & 67 & 94 & $227(5.30)$ & $40(65.24)$ \\
\hline 3 & 19.11. & $14: 43$ & 136 & 56 & 125 & 35 & 132 & 23 & 32 & 5 & 16 & $213(6.92)$ & $0(100)$ \\
\hline 4 & 19.11. & $17: 51$ & 121 & 29 & 86 & 92 & 95 & 50 & 51 & 18 & 10 & $212(6.39)$ & $7(39.66)$ \\
\hline $5^{\mathrm{LED}}$ & 20.11 & $15: 13$ & 119 & 67 & 250 & 84 & 100 & 27 & 19 & 14 & 36 & $202(9.31)$ & $35(100)$ \\
\hline $6^{\mathrm{LED}}$ & 20.11 & 18:05 & 101 & 19 & 137 & 148 & 187 & 15 & 18 & 17 & 16 & $269(9.22)$ & $167(100)$ \\
\hline $7^{\text {LED }}$ & 20.11 & 23:45 & 99 & 37 & 125 & 214 & 162 & 46 & 43 & 19 & 19 & $293(4.08)$ & $46(56.25)$ \\
\hline $8^{\mathrm{LED}}$ & 21.11 & 02:22 & 121 & 22 & 197 & 205 & 194 & 70 & 47 & 15 & 18 & $240(7.74)$ & 33 (66.67) \\
\hline $9^{\mathrm{LED}}$ & 21.11. & 05:41 & 114 & 62 & 249 & 188 & 212 & 107 & 53 & 13 & 21 & $268(3.50)$ & $159(76.62)$ \\
\hline $10^{\mathrm{LED}}$ & 21.11. & 08:25 & 181 & 423 & 576 & 107 & 123 & 179 & 53 & 46 & 53 & $226(2.44)$ & 70 (56.59) \\
\hline $11^{\mathrm{LED}}$ & 21.11 & $12: 17$ & 101 & 43 & 290 & 55 & 118 & 50 & 32 & 16 & 20 & $212(2.32)$ & $18(39.95)$ \\
\hline $12^{\mathrm{LED}}$ & 21.11 & 19:54 & 36 & 29 & 347 & 164 & 215 & 20 & 24 & 16 & 17 & $215(2.73)$ & $93(56.54)$ \\
\hline 13 & 22.11 & 00:52 & 87 & 11 & 146 & 87 & 148 & 24 & 23 & 10 & 11 & $212(3.23)$ & $*$ \\
\hline 14 & 22.11 & 04:07 & 89 & 21 & 102 & 30 & 111 & 53 & 36 & 6 & 4 & $191(3.92)$ & $*$ \\
\hline 15 & 22.11 & 06:20 & 89 & 37 & 115 & 98 & 190 & 85 & 68 & 4 & 9 & $226(5.54)$ & $27(63.37)$ \\
\hline 16 & 22.11 & 10:36 & 40 & 154 & 106 & 23 & 33 & 90 & 22 & 14 & 25 & $230(2.67)$ & $8(59.76)$ \\
\hline
\end{tabular}


Table 2: Size selectivity parameters and fit statistic results for all analyzed species based on fitting the model (2-3) to the experimental data. Values in brackets are $95 \%$ confidence limits. $\mathrm{DOF}=$ Degrees of freedom.

\begin{tabular}{|c|c|c|c|}
\hline Species & Parameter & Without LEDs & With LEDs \\
\hline \multirow{7}{*}{ American Plaice } & \multirow{3}{*}{$\begin{array}{l}C_{\text {grid }} \\
L 50_{\text {grid }}(\mathrm{cm})\end{array}$} & $1.00(0.96-1.00)$ & $0.99(0.95-1.00)$ \\
\hline & & $19.46(18.29-20.98)$ & $19.44(18.55-20.91)$ \\
\hline & & $8.26(6.68-9.53)$ & $8.36(6.84-9.38)$ \\
\hline & $S R_{\text {grid }}(\mathrm{cm})$ & & \\
\hline & DOF & 39 & 42 \\
\hline & Deviance & 25.54 & 54.07 \\
\hline & p-value & 0.9524 & 0.1004 \\
\hline \multirow{7}{*}{ Cod } & \multirow{2}{*}{$C_{\text {grid }}$} & $0.83(0.70-1.00)$ & $0.84(0.77-0.99)$ \\
\hline & & $18.55(15.93-21.46)$ & $18.84(16.89-20.77)$ \\
\hline & \multirow{2}{*}{$\begin{array}{l}L 50_{\text {grid }}(\mathrm{cm}) \\
S R_{\text {grid }}(\mathrm{cm})\end{array}$} & $5.06(1.15-7.31)$ & $3.92(2.04-5.95)$ \\
\hline & & 35 & 32 \\
\hline & DOF & 1508 & 860 \\
\hline & Deviance & 15.90 & \\
\hline & $\mathrm{p}$-value & 0.9976 & 1.0000 \\
\hline \multirow{6}{*}{ Haddock } & \multirow{2}{*}{$C_{\text {grid }}$} & $0.51(0.44-1.00)$ & $0.92(0.46-1.00)$ \\
\hline & & $17.84(14.34-18.07)$ & $15.22(14.22-14.22)$ \\
\hline & $\begin{array}{l}L S 0_{\text {grid }}(\mathrm{cm}) \\
S R_{\text {grid }}(\mathrm{cm})\end{array}$ & $0.50(0.50-4.88)$ & $4.55(0.10-5.49)$ \\
\hline & \multirow{2}{*}{ DOF } & 13 & 10 \\
\hline & & 12.12 & 16.69 \\
\hline & Deviance & 0.5176 & 0.0816 \\
\hline \multirow{7}{*}{ Redfish } & \multirow{4}{*}{$\begin{array}{l}C_{\text {grid }} \\
L 50_{\text {grid }}(\mathrm{cm}) \\
S R_{\text {grid }}(\mathrm{cm})\end{array}$} & $0.78(0.70-0.94)$ & $0.90(0.77-1.00)$ \\
\hline & & $13.98(13.23-14.61)$ & 13.85 (11.86-15.09) \\
\hline & & $2.42(2.42-3.24)$ & $4.07(2.18-5.96)$ \\
\hline & & 39 & 36 \\
\hline & \multirow{2}{*}{ DOF } & & \\
\hline & & 25.54 & 36.79 \\
\hline & $\begin{array}{l}\text { Deviance } \\
\text { p-value }\end{array}$ & 0.9524 & 0.4323 \\
\hline \multirow{7}{*}{ Deep-water Shrimp } & \multirow{4}{*}{$\begin{array}{l}C_{\text {grid }} \\
L 50_{\text {grid }}(\mathrm{mm}) \\
S R_{\text {grid }}(\mathrm{mm})\end{array}$} & $1.00(0.97-1.00)$ & $1.00(0.98-1.00)$ \\
\hline & & $48.87(28.07-197.42)$ & $58.46(35.87-198)$ \\
\hline & & $16.45(0.10-41.74)$ & $20.46(3.27-90.22)$ \\
\hline & & 16 & 18 \\
\hline & DOF & 23.65 & 104.05 \\
\hline & \multirow{2}{*}{ Deviance } & 00074 & 10001 \\
\hline & & $0.09 / 4$ & $<0.001$ \\
\hline
\end{tabular}


Figure 1: Selective system consisting of a Nordmøre grid followed by the codend seen from above (A) and the experimental setup (B) in a side view. A cover is installed over the escape outlet in the upper panel and an inner net is inserted in the codend. Small circles represent $\varnothing 200 \mathrm{~mm}$ plastic floats.

Figure 2: The two trawl configurations tested: Standard configuration without LEDs (top) and standard configuration with four Lindgren-Pitman Electralume ${ }^{\circledR}$ LEDs mounted on the lower part of grid (bottom) pointing in the towing direction and $45^{\circ}$ downwards.

Figure 3: Grid passage probability for all species. Dots illustrate experimental rates, solid curves represent the fitted model, and the dashed curves are the $95 \%$ confidence bands for the curves. Results are presented for the configuration without LEDs (left column), the configuration with LEDs (middle column) and the difference in the length-dependent grid passage probability (Delta) (right column). For bycatch species length is total length in $\mathrm{cm}$ whereas length is carapace length in mm for Deep-water shrimp. Grey solid curves represent total summed (and raised in the case of Deep-water shrimp) population size structure retained by the gear. 
FIG. 1
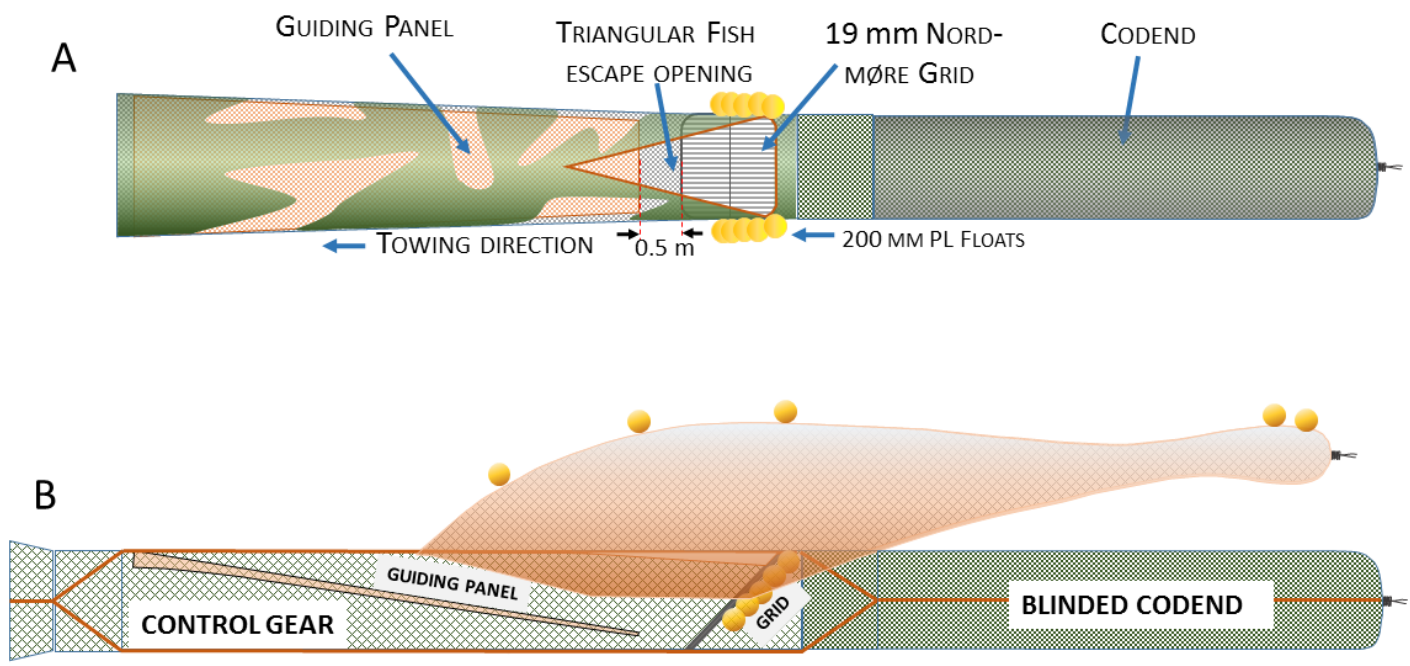

FIG. 2

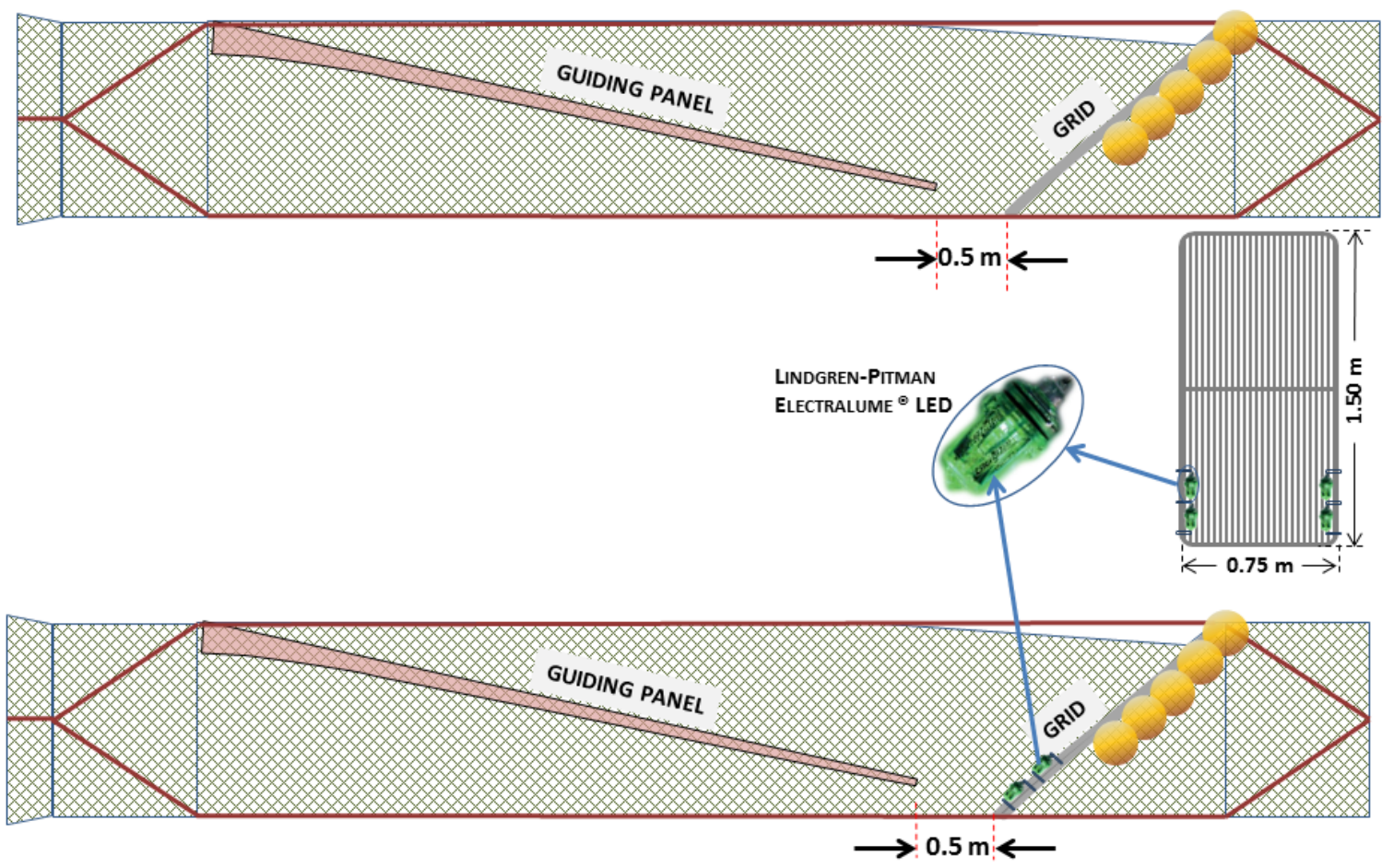


FIG. 3
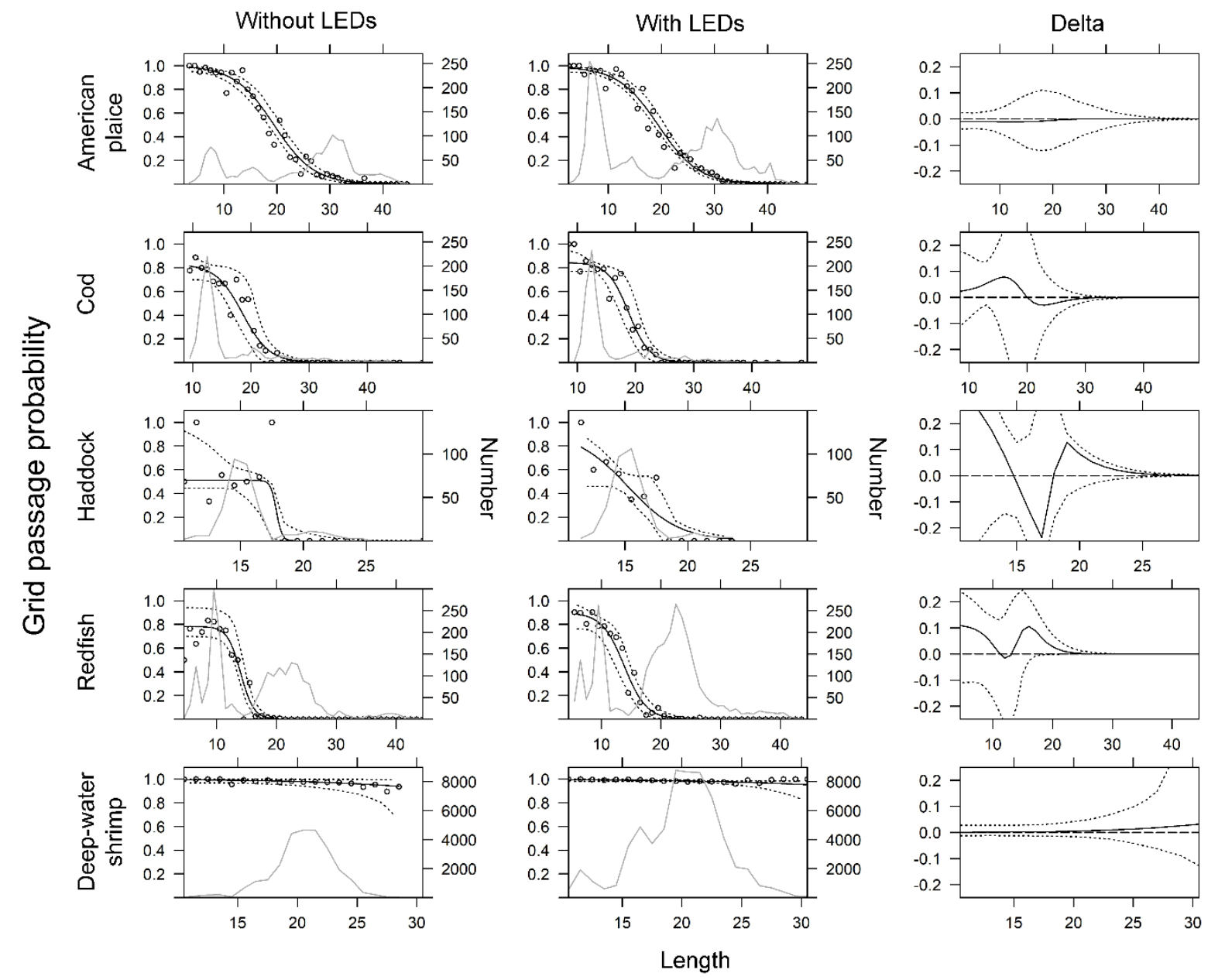